\title{
An Optimized Mathematical Model for Items Supplies Planning of a Logistic System
}

\author{
Mohammad Ali Nasiri Khalili ${ }^{1}$, Mostafa Kafaei Razavi ${ }^{2} \&$ Morteza Kafaee Razavi ${ }^{3}$ \\ ${ }^{1}$ Department of Biosciences and Biotechnology, Malek Ashtar University of Technology, Tehran, Iran \\ ${ }^{2}$ Department of Applied Mathematics, School of Mathematical Sciences, Ferdowsi University of Mashhad, \\ Mashhad, Iran \\ ${ }^{3}$ Department of electrical and biomedical engineering, Sadjad University of Technology, Mashhad, Iran \\ Correspondence: Mostafa Kafaei Razavi, Department of Applied Mathematics, School of Mathematical Sciences, \\ Ferdowsi University of Mashhad, Mashhad, Iran. E-mail: kafaei@staff.um.ac.ir
}

Received: April 4, 2016

Accepted: May 5, 2016

Online Published: July 7, 2016

doi:10.5539/mas.v10n10p133

URL: http://dx.doi.org/10.5539/mas.v10n10p133

\begin{abstract}
Items supplies planning of a logistic system is one of the major issue in operations research. In this article the aim is to determine how much of each item per month from each supplier logistics system requirements must be provided. To do this, a novel multi objective mixed integer programming mathematical model is offered for the first time. Since in logistics system, delivery on time is very important, the first objective is minimization of time in delivery on time costs (including lack and maintenance costs) and the cost of purchasing logistics system. The second objective function is minimization of the transportation supplier costs. Solving the mathematical model shows how to use the Multiple Objective Decision Making (MODM) can provide the ensuring policy and transportation logistics needed items. This model is solved with CPLEX and computational results show the effectiveness of the proposed model.
\end{abstract}

Keywords: logistic, optimization, transportation, mixed integer programming

\section{Introduction}

It is the duty of the military forces to protect the country. In order to carryout military mission, it is urgent to create processes and different systems (Stadler \& Kyluchr, 2005). Military system processes include the three following categories:

1. Processes and management systems (commanding): They contain all steps and activities that control, plane and organize mission and support processes. Commanding and headquarter are samples of management systems.

2. Processes and mission systems: They contain the whole steps and activities that lead to the main organization mission and produce mission outputs. Operational units and teams are examples of these military systems that carry out the main mission of a military system.

3. Processes and support system: They contain the whole steps and activities that support the organization processes and the whole organization in term of different aspect to enable the organization to carry out its mission properly financial system, human resources system, budget system, and logistic systems are some examples of this system in military system.

The scope of this project is related to process and support system. Logistic system acts as a part of support system and is on of military system. One of the main duty of logistic system is to supply military items and it consist of providing and supplying items related to military system mission in order to maintain the ability and get ready the military forces.

Logistic system modeling tries to answer the questions: Who supply the required goods of customers? When? How much?

In this regard, the second section is concerned with explained items supplies system and examines related literature review. The third section presents a perfect mathematical model for making decisions about items 
supplies system. The forth section is concerned with solving this model and the fifth section draw a conclusion.

\section{Problem Definition}

One of the main important features in any supply is goods and items that circulate in the system. This case is of items and goods are importance especially in logistic system with 700000-800000 items. The writer explains the processes and conditions of items supplies system in military logistic.

\subsection{Items Supplies System}

The main aim of supplies in logistic system includes providing and supplying items related to military system missions in order to maintain the ability and get ready the military forces. These items consist of organizational equipment, consumable materials, and soon to this end after determining the needs the required items will be prepared. On the other hand, items will be saved in accordance with the terms of use and users and be given in the support units based on distribution timetable. In order to do these tasks, logical processes of activities, showing the sequence of this operation are drawn in fiqure 1.

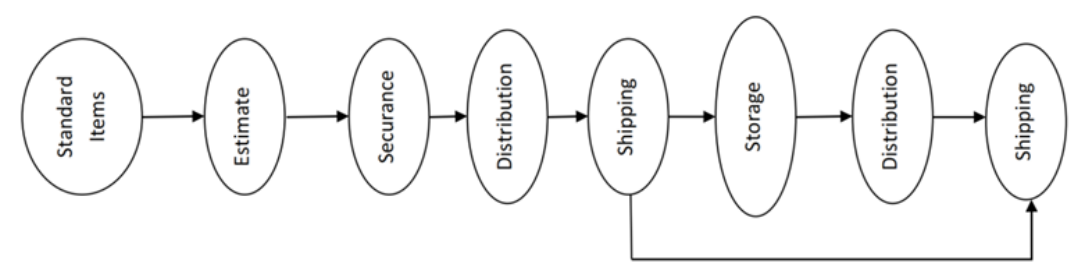

Figure 1. Process activities of items supplies

\subsubsection{Items Standardization}

The aim of this activity is to determine the type, quality, and quantity of items required by military system. In this activity, needs analysis of supported units is done, then, some items are determined based on different parameters in order to meet the required needs, according to these items, it is possible to categorize the organization table of system units and consumption standards. As well, specifications and features of items as items standard are determined and those items that meet these features are selected. According to related criteria, uniformity is done to reduce the items diversity in the organization and items coding is also done to facilitate the logistic functions.

\subsubsection{Estimation}

The purpose of present paper is to determine the amount of required items for supported units. Missions, approved development projects, depreciation and replacement coefficients, and required consumable and organizational items are specified based on items consumption (soft) standard, organization tables and statistic of supported units. Also, percent and allocated budget are determined and approved in terms of items class and finally the required budget is received and allocated.

\subsubsection{Securance}

Required items and their features are specified in the previous stage. As well, required items are allocated to supported units in different classes (organizational or consumable). At this stage of the process, required items are provided through supply centers. The purpose of this activity was to plan the items supply from supply centers and to try to receive the required items from defense industry organization, indoor suppliers, and abroad.

\subsubsection{Distribution}

The purpose of this activity is to distribute items to support units, based on supply program, unit's needs, and policies and priorities, required items are provided. Some of them will be sent to consumers directly and some of them will be sent to storing centers. Then stored items will be sent to supported units.

\subsubsection{Storing}

Due to continuity and consistency of supply chain, important conditions such as production time, items supply, and item delivery in different times will be considered. The aim of this activity is to store the items based on supply program send distribution, in order to receive the items with the long delay in sending. As a result, it is necessary to pay serious attention to the quality and quantity of these warehouses because delay in items delivery creates cases such as deterioration and obsolescence. 


\subsubsection{Items shipping}

By supply centers after supply and items distribution planning by supply centers, shipping agents have to load the items and send them to required destination in time. In the first case, this transition can be done through supply centers such as sassed, production centers of military system and indoor (domestic) factor in addition, this fleet receives the stored items, load, and spaces based on distribution schedule hence. It is necessary to highlight that the scope of this activity includes 3 processes such as items supply from suppliers, Items transition, and items distribution.

\subsection{Describing Network Chain of Logistic Supply}

Network structure (figure2) can be defined as a network chain and each nod is presented as an entity of supply chain. In this supply chain, the focus is, figures 2 and 3 show the current status of physical items in supply chain for delivery items directly and indirectly. It could be said that the first one indicates the traditional status of items and process of items delivery have changed from direct to indirect. In figures 2 and 3, force headquarters as a consumer in division is considered to facilitate the modeling and planning. Similarly division head quarter as a consumer is considered in bridge level. According to planning status, categories below the bridge level are not considered. Nowadays, there is a hybrid mode in other words; there are 3 kinds of delivery as follows: indirect delivery, direct delivery and hybrid delivery (direct and indirect).

\subsection{Importance of Items Categories}

The variety and characteristics of items in the military system cannot be compared to any other systems. In this system there are 700 and 800 thousand kinds of goods that each one can enter the system with permutations. This items diversity may differ in different years. In other words, some parts are fixed and some parts are variable that they may leave or add to the consumption cycle. On the other hand, what is said above does not include the components. In other words If component cases are added to this diversity, items variety increases significantly. For example, an ordinary has nearly 20 or 30 thousand maintenance in supply system. The car is considered as a commodity, but its component (pieces) are not regarded as goods items. In a classification, goods are categorized in 3 classes:

1. Consumer goods (such as clothes).

2. Capital goods (such as tables, chairs, and cars).

3. Military items

a. Main defense items (such as guns and tanks).

b. Non-main defense items (such as ammunition and consumer lending).

There is another approach in items classification driving from its supply source.

1. Domestic resources: These items are purchased or produced in the country and generally they are civil. These kinds of items are called "domestic purchases". These items and their producers live in the country. In some cases, some items are produced by foreign manufacturers but they are exclusive representatives in the country.

2. Outdoor resources: Some parts of items are bought from the outside of the country. Some military and civilian items are provided abroad.

3. Country military industry: Another part of the requirements are provided by other resources called "country military resources". Country military resources is under control of ministry of defense. 


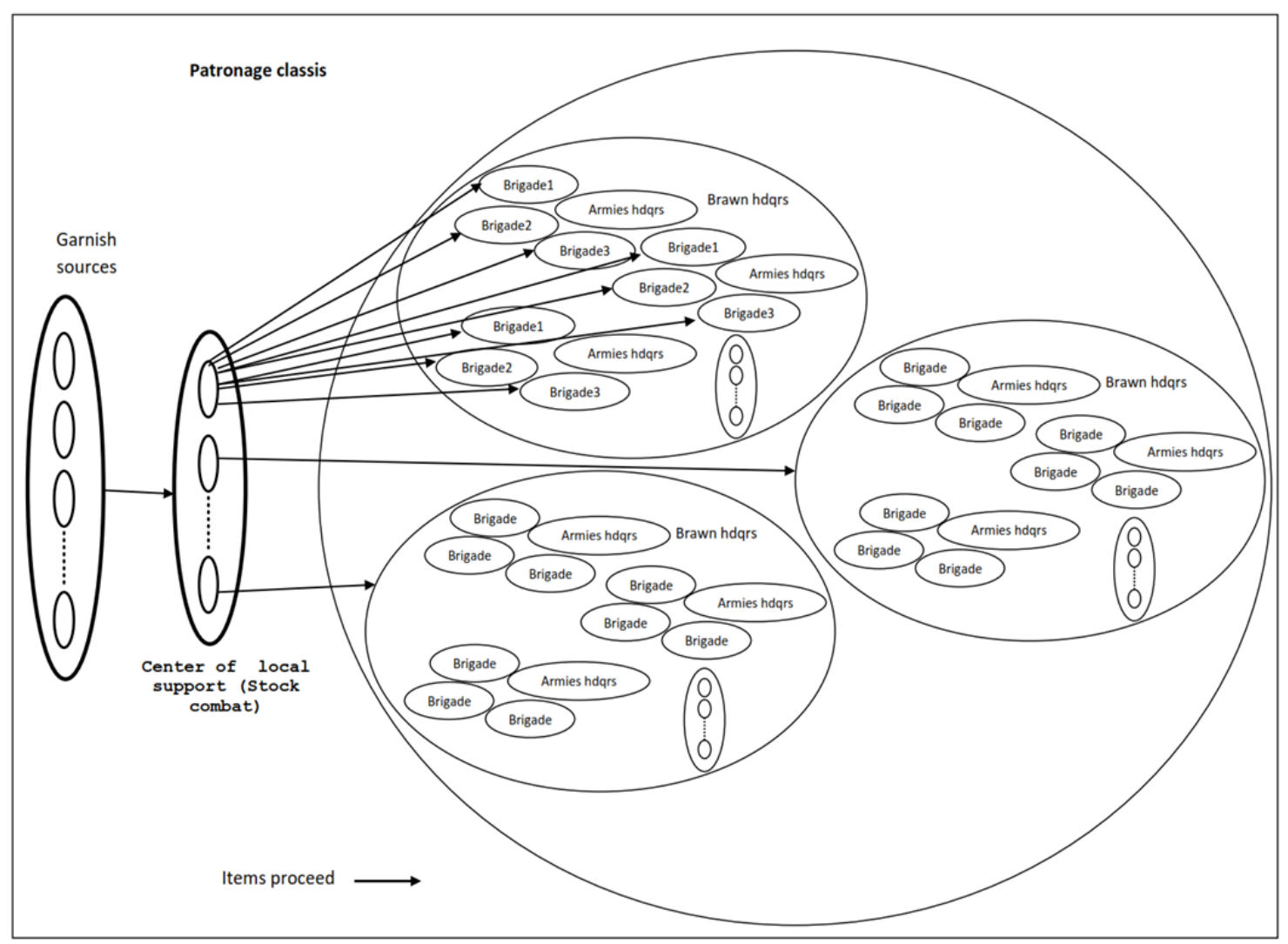

Figure 2. Current status of physical items in a supply chain for delivering items indirectly

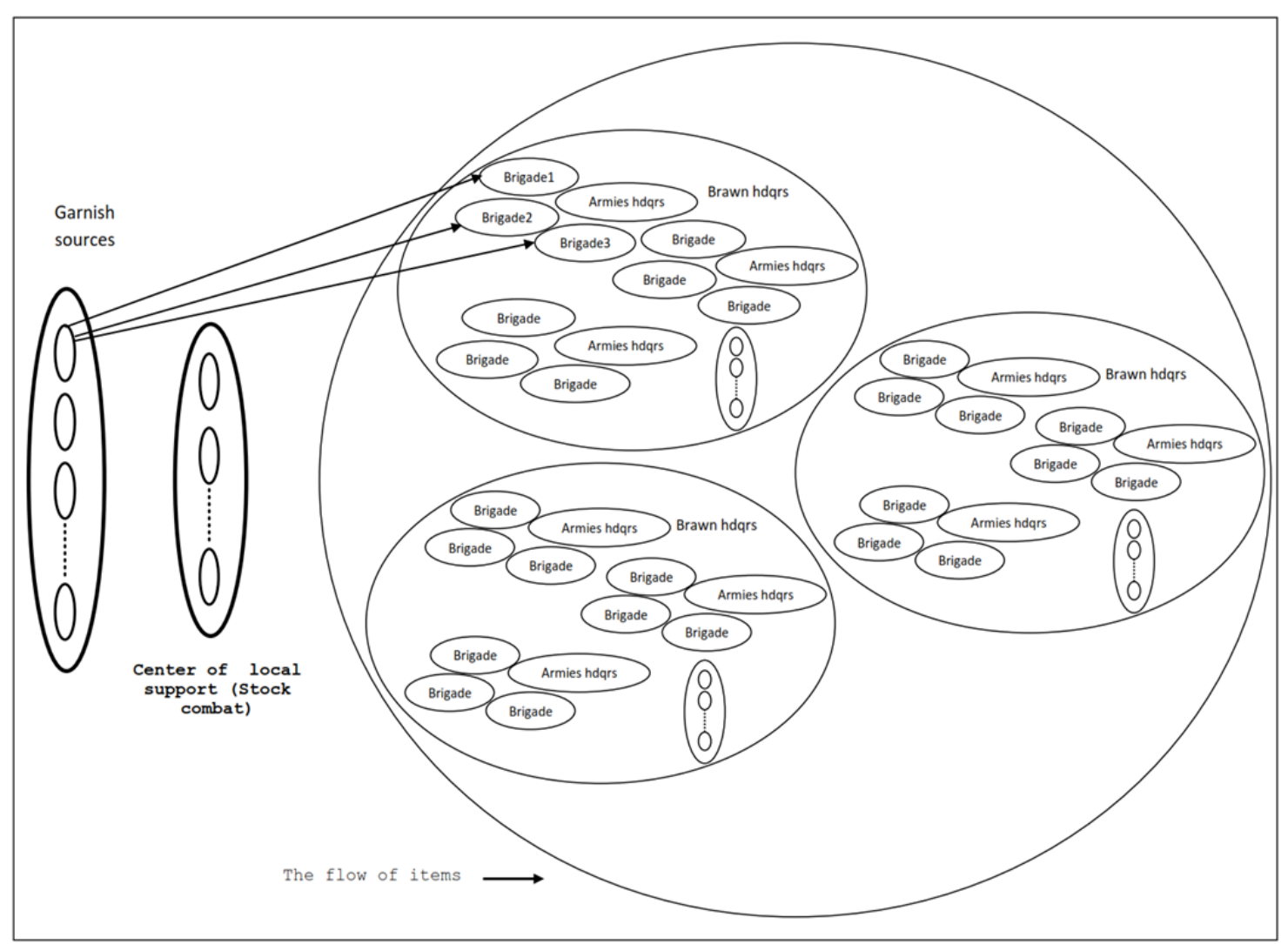

Figure 3. Current status of physical items in a supply chain for delivering items directly 


\subsection{Time Horizon of Supply Items Models}

The planned program should be done in the minimum period of time monthly (month maximally). In other words, the planned models should be considered

\subsection{Scope of the Study}

The scope of the study and the important hypotheses related to this study are as follows:

- In additional to goods, service is one of the entities that is provide in military logistic system and is not concerned in this study.

- Analyzing 20-80 (ABC or Parto) in order to determine a few number of items that include costs and more sensitivity of supply items system. This study was done on items class A.

- $\quad$ The scope of this project consist of items that move eclectically in the network (fig 2 and fig 3 ).

\subsection{Review of the Literature}

Many researches has been done in the world about optimizing systems related to supply, distribution and items transportation that can be used in such studies directly or indirectly.

Speranza \& Ukovich (1993) considered a distribution network including 1 origin and 1 destination. The present study aims at finding transport frequency of each product (use percent of each transport frequency equals delivery of each product while using different transport frequency is allowed for one product) and required transport instrument.

Pas \& Tyagi (1997) concerned with importance of balance focus in one place on several places of balance, the more transport costs and the less time delivery. In this paper, 5 different statuses are considered for saving places.

Heyman \& Hoadley (1977), have considered one balance model of two levels including one storehouse in the first level and several level. The output of this case was level determination of balance related to all storehouse (warehouse) after some adjustments, so that storage costs, balance maintenance, and fast transport minimize.

Berry et al (1998) concerned with planning complicated distribution systems including a number receive and send points. The input data contain demand flow between each pair of points origin-destination costs of per capacity in each way, and limitations Such as maximum flow of traffic in each way and the number of intermediate points. The output is that whether there is a way between two points or not? And then what traffic level should be on each way? The present study suggests using linear plans and genetic algorithm to solve the defined problem.

Jayaraman (1998) considered the relationship between facility location, balance management and determination of transport policies at the same time in a planned environment of distribution network and presented a mathematical model of mixed integer with regard to relationship among these three spaces.

Que et al (1999) examined a distribution network including a central storehouse and a number of suppliers. Demand amount of a store house is uncertain and a modified policy of a period review is used to control the balance In order to solve, the problem is divided into a balance problem and a sub-problem of location. A balance problem for each items is solve able and some (TSP) problems have to be solved to solve a sub-problem of location related to each problem.

Kim \& Kim (1999) examines a single product with a transport device and a limited number of transports. This system includes one central storehouse and retailer that the demand for each retailer is determined in a specified time horizon. It was intended that the timing of goods delivery from retailers, storehouse determined so that the sum of transportation costs from the storehouse to the retailer and balance costs in retailers place minimize, so that retailers do not face any shortages.

Lumsden et al (1999) examines Europe distribution system that distributes goods at the international level. This distribution system works in more than 130 countries and with 44000 human's resources and 80 production centers of goods. In this paper, a two-level heuristic algorithm is suggested.

Gonzalez \& Fernandez (2000) considered distribution systems including several destinations. They are going to determine the amount of sent goods from each origin to each destination and all's determine the vehicle location from each origin in order to minimize the whole costs of transport. The genetic algorithm is used to solve the problem.

Jayaraman and Pirkul (2001) examine supply chain including suppliers, factories, distribution centers, and demand areas with several products and certain demands. They present a model in order to decide 
simultaneously in both strategic and operational levels for establishing facilities, determine areas and transport rate. The objective function is to minimize the costs and a heuristic method is used to solve based on lagrangian relaxation.

Yokoyama (2002) considered a system including several distribution centers and several customers that was loaded from distribution centers to customers based on customer each customer does not have a special distribution center and can receive his/her services from each center. Balance system of distribution centers use policy of period review $\left(\mathrm{R}_{\mathrm{i}}, \mathrm{T}_{\mathrm{i}}\right)$. The purpose of the present study is to find the related $\mathrm{R}_{\mathrm{i}}$ to each distribution center and loading rate from each distribution center to each costumer at any time. For this purpose, a liners model was built to minimize the average transportation costs. In 2002, there are several other papers in the field (Hwang, Zhou et al, Syam and Syarif et al).

Axsater (2003) considered a two-level distribution system including storehouses and retailers. Goods store in storehouses and then deliver to retailers based on their demands and then they are sent to the customer. So there are one balance system in storehouse and other balance systems in storehouses of retailers. Considered balance systems come from two kinds of $\left(\mathrm{R}_{\mathrm{i}}, \mathrm{Q}_{\mathrm{i}}\right)$ permanent review.

Molcashi \& Kokossis (2003) concerned with planning distribution and production in system including a number of production centers and storehouse's goods delivery to customers is done by two channels of direct transport from factory or distribution through storehouses to solve this model. An analysis method of two production problems is used to minimize the distribution costs and the answer using graph theory algorithms are obtained in each model.

Chen \& Lee (2004) examined a supply chain including a number of production centers, distribution centers, and retailers. In this model, some factors such as production rate, transport rates, reasonable level of fee in buyer and sellers view, balance level, and transport capacity are considered. In this model, the multiple objective functions include fair distribution of profits among units, maximizing the service levels of customers, maximizing decision robustness related to above three objective functions in dealing with uncertain demands, and increasing satisfaction level of all partners in terms of agreed fees. To solve this model, a phase decision method is used.

Chan et al (2005) considered a network and a number of manufacturers that should meet the customer demands in a limited production capacity completely. In this system, shortage is not allowed and decisions should be made on transport rates of goods. The multiple objective function were to minimize the costs, to minimize the whole time of delivery as a service level to the costumers and to balance using production capacities among factories.

In this paper, AHP method is used to reach the goals and a genetic algorithm is used to solve the linear model.

In recent years, numerous articles have been working in this field (Abraham et al (2015), Zhang et al (2015), Sukkerd and Wuttipornpun (2016)).

\section{Formulating the Problem}

According to the presented descriptions, discussed problem will be formulated. Network structure of items supply of this study can be considered as figure 4.

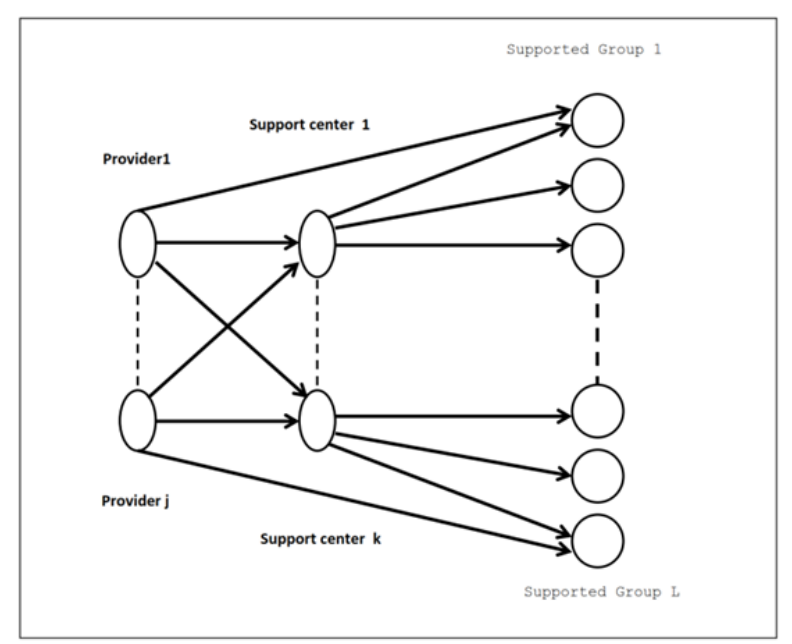

Figure 4. Multi-unit network including several suppliers, several support centers and several supported units 


\subsection{Problem Hypotheses}

Problem hypotheses are considered as follows:

- System includes several regional support centers, several supported units to each regional support center, and some supported units.

- In this model, direct delivery (goods delivery from supply origin to supported units) are provided.

- There are several kinds of goods.

- Goods demands is certain and fixed in each period.

- Shortage consideration is allowed.

- There are several transport vehicles in the system.

- Goods have expiration dates, but it is assumed that new items are delivered by suppliers and entered the physical system of goods.

- Expiration period is integer part of period length.

- Goods delivered by supplies are at the beginning of expiration period (goods are new)

- Transport time of goods is too short and negligible in comparison to period length of planning. If this time is significant, expiration period minus transport time replace expiration period.

- The problem of the present study examines in peace condition (no war).

- Time period of planning is annual and decision period is monthly.

\subsection{Objective Functions}

Note that there are two organization in this problem that are independent lawfully and possessively. They are called items supply in a military logistic system and suppliers. Especially, the problem goals of delivery is as follows:

- Minimizing the delivery costs of items to support units on time (including maintenance and shortage costs) that the owner should be responsible.

- Minimizing transport costs of items in the system that supplier should be responsible.

\subsection{The Mathematical Model}

In this section we present the mathematical model. Sets and indexes used are as follows:

- $\quad$ Sources of supply set, $(j=1, \ldots, J)$

- $\quad$ Center of local support set, $(k=1, \ldots, K)$

- $\quad$ Supported groups set, $(l=1, \ldots, L),\left(l \in k_{l}\right)$

- $\quad$ Time periods set, $(t=1, \ldots, T)$

Variables of this model are as bellow:

$X_{i j k t}$ is the amount of goods of type $\mathrm{i}$ that in period $\mathrm{t}$ is received to k-th support center from $\mathrm{j}$-th supply source.

$Y_{i k l t}$ is the amount of goods of type $\mathrm{i}$ that in period $\mathrm{t}$ is received to l-th supported group from k-th support center. $\left(l \in k_{1}\right)$

$Z_{i j l t}$ is the amount of goods of type $\mathrm{i}$ that in period $\mathrm{t}$ is received to 1 -th supported group from $\mathrm{j}$-th garnish source.

$I_{i l t}$ is availability of goods of type $\mathrm{i}$ in $\mathrm{I}^{\text {th }}$ supported group in start period $\mathrm{t}$.

$B_{\text {ilt }}$ is leakage of goods of type $\mathrm{i}$ in $\mathrm{l}^{\text {th }}$ supported group in start period $\mathrm{t}$.

$n_{j k t}^{(1)}$ is the count of vehicles that is required to transport goods from supplier $\mathrm{j}$ to local support center $\mathrm{k}$ in period $\mathrm{t}$.

$n_{k l t}^{(2)}$ is the count of vehicles that is required to transport goods from local support center $\mathrm{k}$ to supported group 1 in period t.

$n_{j l t}^{(3)}$ is the count of vehicles that is required to transport goods from supplier $\mathrm{j}$ to supported group 1 in period $\mathrm{t}$.

The parameters of this model are as bellow. 
$v_{i}$ is volume of goods unit $\mathrm{i}$.

$a_{i}$ is weight of goods $i$.

$E_{x i}$ is duration of use of the good $\mathrm{i}$

$I_{i L 1}$ is initial balance of goods $\mathrm{i}$ in supported group 1 at beginning of the period $\mathrm{t}$.

$B_{i}$ is the annual budget foreseen for the purchase of goods kind I (in period T)

$S_{j t}$ is capacity constraint for supplier $\mathrm{j}$ in period $\mathrm{t}$.

$S_{i j t}^{\prime}$ is capacity constraint for goods of type $\mathrm{i}$ from supplier $\mathrm{j}$ in period $\mathrm{t}$.

$W_{k t}^{(1)}$ is capacity constraint for delivery of local support center $\mathrm{k}$ in period $\mathrm{t}$.

$W_{l t}^{(2)}$ is capacity constraint for delivery of supported group 1 in period $\mathrm{t}$.

$W_{i k t}^{\prime(2)}$ is space capacity constraint of supported group 1 in period $\mathrm{t}$ for goods type i (allocated storage).

$f^{v}$ is volume capacity of vehicle $\mathrm{m}$.

$f^{a}$ is weight capacity of vehicle $\mathrm{m}$.

$d_{i l t}$ is request of supported group 1 of good $\mathrm{i}$ in period $\mathrm{t}$.

$h_{i k t}^{(1)}$ is maintenance cost of one unit of good i by local supported center $\mathrm{k}$ in one period $\mathrm{t}$.

$h_{i l t}^{(2)}$ is maintenance cost of one unit of good $\mathrm{i}$ by supported group 1 in one period $\mathrm{t}$.

$A_{\text {ilt }}$ is lacking cost of one unit of good $\mathrm{i}$ by supported group 1 in one period $\mathrm{t}$.

$C_{i j t}$ is purchase price one unit of good i by supplier $\mathrm{j}$ at period $\mathrm{t}$.

$G_{j k t}^{(1)}$ is price movement of a vehicle from supplier $\mathrm{j}$ to local support center $\mathrm{k}$ at period $\mathrm{t}$.

$G_{k l t}^{(2)}$ is price movement of a vehicle from local support center k to supported group 1 at period $\mathrm{t}$.

$G_{j l t}^{(3)}$ is price movement of a vehicle from supplier $\mathrm{j}$ to supported group 1 at period $\mathrm{t}$.

$E_{i l t}$ is minimum stock of goods $\mathrm{i}$ at the end of period $\mathrm{t}$ for supported group $\mathrm{l}$.

The mathematical model is given below:

$$
\begin{aligned}
\min Z_{1}= & \sum_{i} \sum_{k} \sum_{t} h_{i k t}^{(1)} \cdot \sum_{j} X_{i j k t}+\sum_{i} \sum_{l \in k_{l}} \sum_{t} h_{i l t}^{(2)} \cdot I_{i l t} \sum_{i} \sum_{l} \sum_{t} \partial_{i l t} \cdot b_{i l t} \\
\min Z_{2}= & \sum_{j} \sum_{k} \sum_{t} G_{j k t}^{(1)} \cdot n_{j k t}^{(1)}+\sum_{k} \sum_{l} \sum_{t} G_{k l t}^{(2)} \cdot n_{k l t}^{(2)} \\
& +\sum_{k} \sum_{l} \sum_{t} G_{k l t}^{(3)} \cdot n_{k l t}^{(3)}
\end{aligned}
$$

S.t.

$$
\begin{array}{ll}
\sum_{k} x_{i j k t}+\sum_{l} Z_{i j l t} \leq S_{i j t}^{\prime} \quad & \forall i, j, t \\
\sum_{i} \sum_{k} x_{i j k t}+\sum_{i} \sum_{l} Z_{i j l t} \leq S_{j t} \quad \forall j, t & \\
\sum_{I} \sum_{K} x_{i j k t} \leq W_{k t}^{(1)} \quad \forall k, t & \\
\sum_{k} \sum_{i} y_{i k l t}+\sum_{j} \sum_{i} Z_{i j t l} \leq W_{l t}^{(1)} & \forall l \in k_{l}, \forall t
\end{array}
$$




$$
\begin{aligned}
& \sum_{j} x_{i j k t} \leq W_{i k t}^{\prime(1)} \quad \forall i, k, t \\
& \sum_{k} k_{i k l t}+\sum_{j} Z_{i j l t} \leq W_{i l t}^{\prime(2)} \quad \forall i, \forall l \in k_{l}, \forall t \\
& I_{\text {ilt }} \geq E_{\text {ilt }} \quad \forall i, l, t \\
& n_{j k t}^{(1)}-1 \leq \frac{\sum_{i} X_{i j k t} \cdot V_{i}}{f^{v}} \leq n_{j k t}^{(1)} \quad \forall j, k, t \\
& n_{j k t}^{(1)}-1 \leq \frac{\sum_{i} X_{i j k t} \cdot a_{i}}{f^{a}} \leq n_{j k t}^{(1)} \quad \forall j, k, t \\
& n_{k l t}^{(2)}-1 \leq \frac{\sum_{i} y_{i k l t} \cdot V_{i}}{f^{v}} \leq n_{k l t}^{(2)} \quad \forall k, \forall l \in k_{l}, \forall t \\
& n_{k l t}^{(2)}-1 \leq \frac{\sum_{i} y_{i k l t} \cdot a_{i}}{f^{a}} \leq n_{k l t}^{(2)} \quad \forall k, \forall l \in k_{l}, \forall t \\
& n_{j l t}^{(3)}-1 \leq \frac{\sum_{i} z_{i j l t} \cdot V_{i}}{f^{v}} \leq n_{j l t}^{(3)} \quad \forall j, \forall l \in k_{l}, \forall t \\
& n_{j l t}^{(3)}-1 \leq \frac{\sum_{i} z_{i j l t} \cdot a_{i}}{f^{a}} \leq n_{j l t}^{(3)} \quad \forall j, \forall l \in k_{l}, \forall t \\
& \sum_{j} x_{i j k t}=\sum_{l \in k_{K}} y_{i k l t} \quad \forall i, k, t \\
& I_{i l 1}+\sum_{k} \sum_{t} y_{i k l t}+\sum_{j} \sum_{t} z_{i j l t}=\sum_{t} d_{i l t} \quad \forall i, \forall l \in k_{l} \\
& \sum_{t} \sum_{j} \sum_{k} C_{i j t} \cdot x_{i j k t}+\sum_{t} \sum_{j} \sum_{k} C_{i j t} \cdot z_{i j l t} \leq B_{l} B_{i} \quad \forall i \\
& I_{\text {ilt }} \cdot b_{\text {ilt }}=0 \quad \forall i, l \in k_{l, t} \\
& \sum_{t^{\prime}=1}^{t} \sum_{k} y_{i k l t^{\prime}}+\sum_{t^{\prime}=1}^{t} \sum_{j} z_{i j l t^{\prime}}-\sum_{t^{\prime}=1}^{t} d_{i l t^{\prime}}=I_{i l t}-b_{i l t} \quad \forall i \in k_{l}, t \\
& \sum_{t^{\prime}=1}^{t} \sum_{j} x_{i j k t^{\prime}}+\sum_{t^{\prime}=1}^{t} \sum_{j} \sum_{l \in k_{l}} z_{i j l t^{\prime}} \leq \sum_{\mathrm{t}^{\prime \prime}=1}^{\min \left(t+E_{x_{j}}, T\right)} \sum_{l \in k_{l}} d_{j l t^{\prime \prime}} \forall i, k, t \\
& \sum_{t^{\prime}=1}^{t} \sum_{j} x_{i j k t^{\prime}} \leq \sum_{\mathrm{t}^{\prime \prime}=1}^{\min \left(t+E_{x_{j}}, T\right)} \sum_{l \in k_{l}} y_{j k l t^{\prime \prime}} \forall i, k, t \\
& I_{i l t}, b_{i l t}, x_{i j k t}, y_{i k l t}, z_{i j l t} \geq 0 \quad \forall i, j, k, \forall l \in k_{l}, \forall t \\
& n_{j k t}^{(1)}, n_{k l t}^{(2)} \in Z^{+} \quad \forall i, j, k, \forall l \in k_{l}, \forall t
\end{aligned}
$$

Equation (1), the objective function is the logistic system that minimizes the shortage and maintenance of costs. This objective function shows implicitly the delivery costs one time [35]. Note that there maintenance costs for regional support centers and support units while the shortage costs go for final consumer (supported units). 
Purchase costs calculated as follows:

$$
\sum_{i} \sum_{j} \sum_{k} \sum_{t} C_{i j t} \cdot x_{i j k t}+\sum_{i} \sum_{j} \sum_{l} \sum_{t} C_{i j t} . z_{i j l t}
$$

Because of the great importance of timely delivery in military issues in comparison to purchase costs and due to significance difference in purchase price of items from different suppliers for several years, these costs are not considered in the objective function. One the other hand, an objective function not only represent one-time delivery but also enables the analysis of the future sensitivities.

Equation (2), the objective function of suppliers is to minimize the transport costs. Suppliers are independent lawfully and the exact equation is that each suppliers has an objective function. Because the weight of all suppliers are equal in this supply chain and due to the analysis and calculating easiness of the problem, all of this costs are calculated equally.

Equation (3), considered capacity limitation of suppliers supply and expresses that the whole order rate of a certain item to a certain suppliers in each period should not be more than the whole supply capacity of suppliers of that item in that period.

Equation (4), considers capacity limitation of suppliers supply and expresses that the whole order rate of goods to a certain supplier in each period should not be more than the whole supply capacity of suppliers in that period.

Equation (5), considers the whole capacity limitation of storehouse of each regional supported center and expresses that the balance rate of goods should not be more than storehouse capacity in each period.

Equation (6), considers the whole capacity limitation of storehouse in each supported unit and expresses that the balance rate of a goods in each period should not be more than storehouse capacity.

Equation(7), considers allocated capacity limitation of storehouse of each regional support center and expresses the balance rate of each item in each period should not be more than allocated capacity of storehouse in each center.

Equation (8), consider allocated capacity limitation of storehouse of each supported unit and expresses that balance rate of each item in each period should not be more than allocated capacity of storehouse in each center.

Equation (9), shows that balance rate of each item for each supported unit in each period should be less than the required balance rate of that item at the end of that period.

Equations (10) and (11), estimates the number of transport vehicles required by each suppliers for delivering to each regional support center in each period.

Equations (12) and (13), estimates the number of transport vehicles required for each regional support center for delivering to each supported unit in each period.

These limitations help to use the whole capacity of transport vehicles maximally with the aid of the objective function.

Equation (12), considers the volume limitation of transport vehicles end.

Equation (13), considers the weight limitation of vehicles.

Equations (14) and (15), estimates the number of transport vehicles required by each supplier for delivering to each supported unit in each period. These limitation help to use the capacity of transport vehicles maximally with the aid of the objective function

Equation (14), considers the volume limitation of transport vehicle and considers the weight the weight limitation of vehicles.

Equation (16), is the survival equation in each regional support center.

Equation (17), expresses the activated limitation of demand of supported units for each unit in the whole period $\mathrm{T}$.

Equation (18), expresses the budget limitation for each item.

Equation (19), expresses that each item and each supported unit in each period or each balance rate are none-negative that is both variable never become positive together. This limitation is non-linear. So, we replace the other limitation such as: 


$$
I_{i t} \leq M . y_{i t} ; \quad b_{i t} \leq M\left(1-y_{i t}\right) \quad \forall i, t
$$

$\mathrm{M}$ is a very large number and $\mathrm{y}_{\mathrm{it}}$ is a variable zero and one.

Equation (20), expresses the relationship between the received order rate from required goods of each supported unit and the situation of that item.

Equations (21) and (22), is that the goods to be used in an appropriate consumption date.

Equation (23) and (24), shows that balance rate and shortage rate of supported units for each item in each period, received order rate from each supplier and for each supply center in each period and received order by supported units be positive and the number of vehicles should be in integer number.

\section{Solution Model}

In this part, we discuss the solution method of planned mathematical model of the previous section.

\subsection{Data}

In this part, a brief summary of calculating and estimation of model parameters are presented:

Size and weight of the items: Size and weight of each items and consumption period of each item are parts of the specification of each item that are calculated and announced by suppliers.

Initial budget: Initial budget of each supplied unit from each unit is available and clear in the information system of the beginning of the period.

Annual budget: Determined annual budget is determined to buy each item by logistic system in accordance with the needs of that organization and budget limitation of the whole logistic. The whole logistic budget is determined by the ministry of defense.

Capacity of supplier supply: Capacity limitation of supplier supply in each period and capacity limitation of goods supply in each period in accordance with previous backgrounds of suppliers and examination in logistic system on made contract between suppliers and logistic systems are clear.

Delivery and space capacity: Capacity limitation of delivering of each regional supported center in each period, space capacity limitation of delivering of each regional supported unit in each period, Capacity limitation of delivering of each regional support center in each period, related to each type and Capacity limitation of delivering of each supported unit in each period related to each type of goods are parts of planning features of storehouses. That are clear base on delicate storage [33] and technical features of docks. It is necessary to say that delicate storage is used because the studied items in this application is part of category "A" in Parto analysis. The less important items are not discussed in this project. A randomized storage is used for them.

Vehicle capacity: Weight and size capacity of each vehicles is announced by agencies and making contract between suppliers and their agent are listed.

Demand rate items: Estimating demand rate of items in estimations sub-system is done (it is introduced in part 1 and 2) and the related data are available. It is done in accordance with table including standard norms of consumption items in military systems and a few numbers of simple factors related to norm calculating.

Maintained costs: Logistic systems are responsible for storehouse ownership in regional support centers and supported units. So, logistic system does not pay any costs for maintaining the items. But these costs are a burden on logistic system.

The most important parts of maintenance costs in this system are given blow:

Renting costs of space: Owners of private storehouses are asked about renting costs of space and are used in the model.

Delivery costs: Generally, this cost in logistic system includes movement inside the storehouse, ways and vehicle costs. Type and number of vehicles and personnel in storehouses of logistic system are clear and ways, equipment values, type and depreciation period and annual loss are available and registered.

Capital costs: In this study, the capital costs are considered about $20 \%$ the value of available items in storehouse that are accessible in this environment now.

AL bet costs such as depreciations costs are parts of maintenance costs, but we do not have these costs because of the observance of the expiration date of products. Taxes and insurance costs are parts of maintenance costs, but logistic system as a subsystem of government is exempt. 
Shortage costs: Basically, shortage is not allowed in the state of war and there will be no cost under this name. As it is said, this case study is for the state of peace and there is the possibility of shortage in this condition.

In this system, shortage is called deficiency. In other words, required demands of supported units should be provided sooner or later. Available items in system are provided from manufacturing factories or supply origins of wholesale with low price and consumers (have supported units) receive them after adding costs such as storage and transport costs. If supported units face the shortage, they can provide their required consumption items from local retailers but in higher prices. Here, the difference between final prices for providing items by logistic system and providing items by local retailers is the estimation basis of shortage costs.

Purchase costs: The purchase costs of each item from each supplier in each period is on the basis of purchase prices from suppliers at the beginning of planning period. In the inquiries, annual contracts are made with suppliers transport costs. These items are carried by transport agencies that have independent ownership, but they are not parts of examined supply chain (as third party logistics provider). The costs are paid by suppliers to transport agencies. The amount of annual costs is determined by related unions to transport agencies calculate these costs as follows:

\section{Model Solution}

The model is coded and solved with CPLEX 12.2. This model has $(\mathrm{IT}(2 \mathrm{~L}+\mathrm{JK}+\mathrm{KL}+\mathrm{JL}))$ continuous variable, $(\mathrm{KT}(\mathrm{J}+\mathrm{L}))$ integers variable and (IT) binary variable, limitation number of this model equals: $((\mathrm{IJ}+4 \mathrm{IK}+4 \mathrm{IL}+2 \mathrm{KL}+2 \mathrm{JK}+2 \mathrm{JL}+\mathrm{J}+\mathrm{K}+\mathrm{L}+\mathrm{I}) \mathrm{T}+\mathrm{IL}+\mathrm{I})$

Table (1) shows the mathematical model based on number variable types and number of limitation. As it can be seen variable numbers and model limitation will be a lot with regard to the maximum size of solved problem in literature, tables (2) and (3) shows the size of these for two-unit and three-unit examples. Calculating studies shows:

- Limitation release of integer (number) variables, for both types of the objective function, does not change the amount of the objective function significantly. This case is replaced because of the large volumes of items and a large number of trucks are need. So, we focus on relaxed problem.

- Limitation release of integer variable, for both types of the objective function, creates a significant improvement in the calculated time.

It should be noted that the weight amount of objective function in different categories of items are different in accordance with sensitivity rate of the items for military logistic sensitive items have more weight on on-time delivery target .

\section{Model implementation}

In this part we discuss in association with benefits, problems and consideration of model implementation.

\subsection{Benefits}

Using this mathematical model, extraction time of programs supply is faster than present situation. It should be noted that the current states the new program is planned based on experience and is revised based on last year program. Supplier cost in suggested is less than in current situation nearly on time. Delivery cost in suggested situation is less than in current situation. In spite of this mathematical model, it is possible to up to date the model data according to recent month and revise the program in a short period of time again .In order to do to do this, this spend time equals the time of creation of a new program, while using mathematical model, this task spend the same time using the computer to solve the mathematical model. If it is needed to create programs with a period time larger or smaller than a year or periods whit a size smaller or larger than a month, mathematical model accept this change without any fundamental changes. Answer drive from mathematical model is defendable and it does not depend on one person, experiences. By the way, the problem of experience transport to new planners are reduced.

\subsection{Implementation Problem}

The main problem of implementation is the bulk of data that should be enter the computer especially for the first use of this model .few data did not use with this volume in the present state, and many calculations was done partly based on experience. Geographic distribution of suppliers, regional support storehouses, supported unit in the country and requirement of updating the whole model parameters need a broad and integrated network. mathematical model does not considered the real word features such as items quality and suppliers 
background .In the some cases some political and social problems occur that are seen this model. So, sometimes it is necessary to pay attention to output of model computers taking into accounts these considerations manually.

In the current situation, some limitation are violated in practice, for example, a large volume of expired items are discarded at the end of year while the probable repeat of this case is reduced with the aid of mathematical model, and if model parameters are consistent with the reality this situation will never occur.

\subsection{Consideration of the Implementation Model}

- According to the criteria such as volume, monetary value and sensitivity items are categorized based on A, $\mathrm{B}$ and $\mathrm{C}$. This mathematical model is used for items class A.

- The available items in logistic system are delivered in forms of two-unit delivery, two-unit indirect delivery and three-unit delivery due to their nature as non can see in figures (4), (5) and (6).This model is used for available items in combined delivering. However it is possible to use this model for other two modes.

- A System classifications of supply items are given below that this classification do not have the same suppliers and they can be used separately for each class.

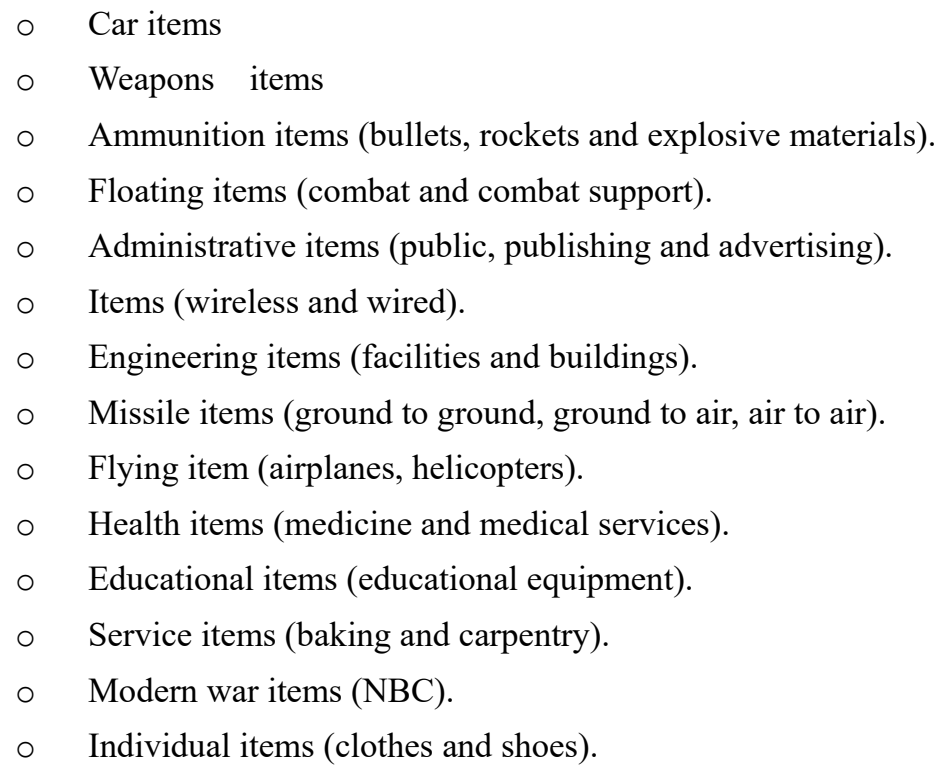

Figure (5), unite network including several suppliers several support center and several supported unit whit indirect delivering.

In military logistic system, using produced item by domestic makers have higher priorities.so the items that the capacity of their domestic production is enough to meet the customers, mathematical model is used separately the items are imported to overcome the indoor production shortages.

Calculation results about relaxed variable of integer number shows that (in part 4) the objective function do not change significantly .while the computational time reduces significantly.

Variable zero and one in a model, limitation nature related to them so that they affect the performance time reasonably.

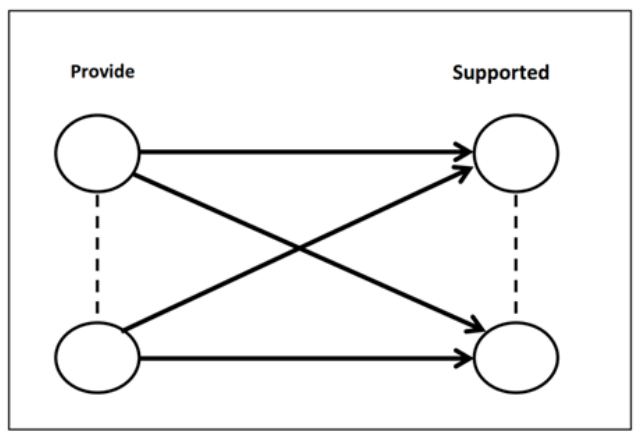

Figure 5. Periodic network consist of several provider, several supported groups with direct dispatch 


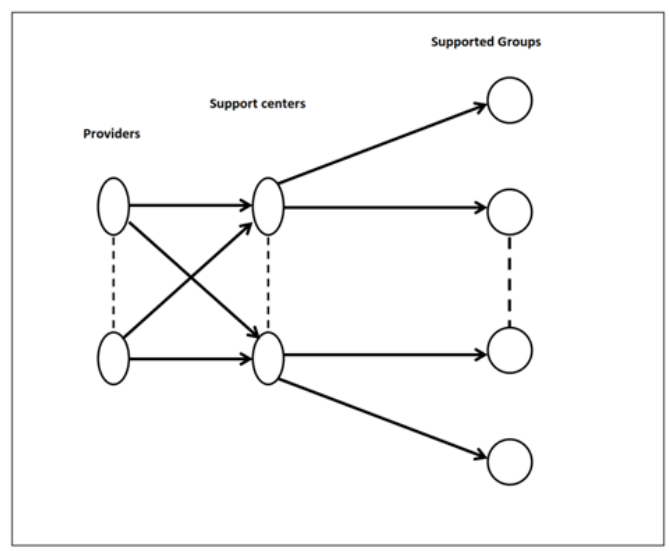

Figure 6. The network of one group consist of several provider, several support center and several supported groups with indirect dispatch

\section{Discussion and Conclusion}

In this study item supply planning of a real military and logistic system and examined. In this system of items supply, there were two types of lawful ownership including logistic system and suppliers. Logistic systems was going to minimize the on-time delivery costs and suppliers also tried to minimize transport costs.in this study, mathematical model type MIP was mode to determine to what extent the goods required by logistic system are provided from suppliers. Solving the mathematical model shows that two models are inconsistent with each other and using MODM methods are allowed .Although model solution in impossible in items of computational time in real space, integer variables released and research present implementation problems and suggestions for implementation model.

Table 1. Information of three groups sample problems

\begin{tabular}{|c|c|c|c|c|c|c|c|c|c|c|}
\hline 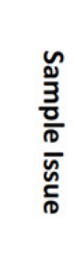 & $\begin{array}{l}\frac{0}{5} \\
\text { ñ } \\
\frac{0}{3} \\
\frac{1}{\omega} \\
\frac{1}{3}\end{array}$ & 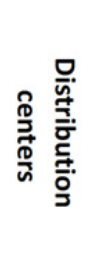 & $\begin{array}{l}2 \\
\stackrel{2}{5} \\
2 \\
0 \\
0 \\
0 \\
0 \\
0 \\
\frac{1}{0} \\
\frac{0}{0} \\
\frac{0}{3}\end{array}$ & 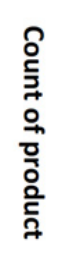 & 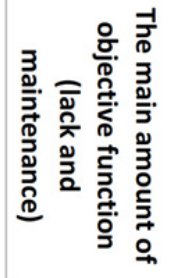 & 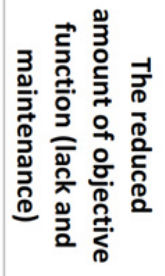 & 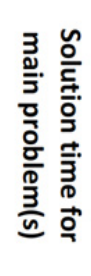 & 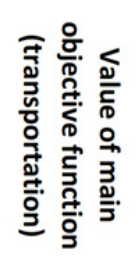 & 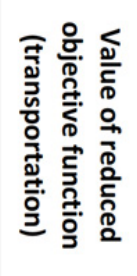 & 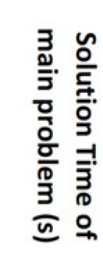 \\
\hline 1 & 1 & 1 & 1 & 1 & 0 & 0 & 3 & 6993 & 6988.16 & 0 \\
\hline 2 & 1 & 1 & 1 & 2 & 12922100 & 12922120 & 1 & 40018 & 40101.15 & 15 \\
\hline 3 & 2 & 1 & 1 & 1 & 2242833 & 2242833 & 100 & 73628 & 73595.25 & 20 \\
\hline 4 & 1 & 2 & 1 & 1 & 3671791 & 3671791 & 8 & 51432 & 51429.4 & 1 \\
\hline 5 & 1 & 1 & 1 & - & 3671794 & 3671794 & 3 & 79005 & 78944.4 & 22 \\
\hline 6 & 2 & 2 & 1 & - & 2097939 & 2097939 & 1 & 2698 & 2683.4 & 1 \\
\hline 7 & 2 & 1 & 1 & - & 8696251 & 8696251 & 1 & 22658 & 22648.2 & 5 \\
\hline 8 & 2 & 1 & 2 & - & 6500410 & 6500410 & 1 & 59730 & 59673 & 18620 \\
\hline 9 & 1 & 2 & 1 & - & 52143500 & 52143500 & 0 & 8454 & 8420.6 & 1 \\
\hline 10 & 1 & 2 & 2 & - & 445458 & 445458 & 0 & 8051 & 8040 & 13 \\
\hline 11 & 1 & 1 & 2 & - & 10813530 & 10813530 & 0 & 12761 & 12647.95 & 6022 \\
\hline 12 & 2 & 2 & 1 & - & 7548885 & 7548885 & 206 & 88011 & 87983.1 & 9863 \\
\hline
\end{tabular}


Table 2. The size of two group sample problems

\begin{tabular}{|c|c|c|c|}
\hline resource & customers & suppliers & products \\
\hline Qu et al. (1999) & 1 & 7 & $15-50$ \\
\hline Hwang (2002) & $50-99$ & 4 & 1 \\
\hline Zhou et al. (2002) & 100 & 10 & 1 \\
\hline Syam (2002) & 20 & 100 & 5 \\
\hline Wang et al. (2003) & 2 & 2 & 2 \\
\hline Miranda and Garrido (2004) & 20 & 10 & 1 \\
\hline
\end{tabular}

Table 3. The size of three groups sample problems

\begin{tabular}{|c|c|c|c|c|}
\hline resource & customers & Distribution centers & suppliers & products \\
\hline Sabri, Beamon (2000) & 5 & 4 & 3 & 2 \\
\hline Jayarama, Pirkul (2001) & 75 & 15 & 5 & 10 \\
\hline Syarif et al. (2002) & $50-100$ & $8-12$ & $6-15$ & 1 \\
\hline Jayarama, Ross (2003) & $30-75$ & $10-15$ & 5 & $2-3$ \\
\hline Li and Savachkin (2013) & 201 & 21 & 1 & 1 \\
\hline
\end{tabular}

\section{References}

Abraham, A. J., Ratna Kumar, K., Sridharan, R., \& Singh, D. (2015). A Genetic Algorithm Approach for Integrated Production and Distribution Problem. Procedia Social and Behavioral Sciences, 189,184-192.

Axsater, S. (2003). Approximate optimization of inventory- distribution systems by random local search and a genetic algorithm. Computers and Industrial Engineering, 42, 175-188.

Berry, L. M., Murtagh. B. A., Sugden, S. J., Mcmahon, G. B., \& Welling, L. D. (1998). Genetic algorithms in the design of complex distribution networks. International Journal of Physical Distribution and Logistics, 28(5), 377-381.

Chan, F. T. S., Chung. S. H., \& Wadhwa, S. (2005). A hybrid genetic algorithm for production and distribution. Omega, 33(4), 345-355.

Chen, C., \& Lee, W. (2004). Multi-objective optimization of multi- echelon supply chain networks with uncertain product demands and prices. Computers and chemical Engineering, 28, 1131- 1144.

Das, C., \& Tyagi, R. (1997). Role of inventory and transportation costs in determining the optimal degree of centralization, Transportation Research Part E. Logistics and Transportation Review, 33(3), 171-179.

Fahn, M., \& Hadjer, T. (2015). Optimal contracting with private military and security companies. European Journal of Political Economy, 37, 220-240.

Farahani, R. Z., \& Asgari, N. (2005). Combination of MCDM and Covering Techniques in Hierarchical Model for Facility Location: A Case Study. European Journal of Operations Research.

Genus, J., \& Zeng, A. Z. (2003). Optimizing Supply shortage decisions in base stock distribution operations. Journal of Global Optimizing, 26, 25-42.

Gonzales, E. L., \& Fernandez, M. A. R. (2000). Genetic optimization of a fuzzy distribution model. International Journal of Physical Distribution and Logistics, 30(7/8), 681-696.

Heyman, D. P., \& Hoadley, B. (1977). A two- echelon inventory model with purchases, disposition shipments, returns and transshipments. Naval Research Logistics Quartely, 24, 1-19.

Hwang, C. L., \& Lin, M. A. S. M. (1979). Multiple Attribute Decision Making, Springer- Verlag. 
Hwang, C. L., \& Lin, M. L. (1987). Group Decision Making under Multiple Criteria, Springer- Verlag.

Hwang, C. L., \& Yoon, K. (1981). Multiple Attribute Decision Making, springer- Verlag.

Hwang, H. S. (2002). Design of supply chain logistics system considering service level. Computers and Industrial Engineering, 43, 283-297.

Jayaraman, V. (1998). Transportation, facility location and inventory issues in distribution network design. International Journal of Operations and Production Management, 18(5), 471-494.

Jayaraman, V., \& Pirkul, H. (2001). Planning and coordination of production and distribution facilities for multiple commodities. European Journal of Operational Research, 133, 394-408.

Jayaraman, V., \& Ross, A. (2003). A simulated annealing methodology to distribution network design and management. European Journal of Operational Research, 144, 629-645.

Kim, J. U., \& Kim, Y. (1999). A decomposition approach to a multi- period vehicle scheduling problem. Omega 24(4), 421-430.

Li, Q., \& Savachkin, A. (2013). A heuristic approach to the design of fortified distribution networks, Transportation Research Part E: Logistics and Transportation Review, 50, 138-148.

Lumsden, K., Dallari, F., \& Ruggeri, R. (1998). Improving the efficiency of the hub and spoke system for the SKF European distribution network. International Journal of Physical Distribution and Logistics 29(1), 50-64.

Miranda, P. A., \& Garrido, R. A. (2004). Incorporating inventory control decisions into a strategic distribution network design model with stochastic demand. Transportation Research: Part E, 40, 183-207.

Mokashi, S. D., \& Kokossis, A. C. (2003). Application of dispersion algorithms to supply chain optimization. Computers and Chemical Engineering, 27, 927-949.

Önal, H., Woodford, P., Tweddale, S. A., Westervelt, J. D., Chen, M., Dissanayake, S. T. M., \& Pitois, G. (2016). A dynamic simulation/optimization model for scheduling restoration of degraded military training lands. Journal of Environmental Management, 171, 144-157.

Qu, W., Bookbinder, J. H., \& Iyogun, P. (1999). An integrated in inventory- transportation system with modified periodic policy for multiple products. European Journal of Operation Research, 115, 254269.

Speranza, M.G. and Ukovich, W., (1993). Minimize transportation and inventory costs for several products on a single link. Operation Research 42(5) 879-894.

Stadtler, H., \& Kilger, C. (2005). Supply Chain Management and Advanced Planning, Springer Verlag, Berlin.

Sukkerd, W., \& Wuttipornpun, T. (2016). Hybrid genetic algorithm and tabu search for finite capacity material requirement planning system in flexible flow shop with assembly operations. Computers \& Industrial Engineering, 97, 157-169.

Syam, S. S. (2002). A model and methodologies for the location problem with logistical components. Computers and Operations Research, 29, 1173-1193.

Syarif, N., Yun, Y., \& Gen, M. (2002). Study on multistage logistics chain network: a spanning treebased genetic algorithm approach. Computers and Industrial Engineering, 43, 299-314.

Szidarovszky, F., Gershon, M. E., \& Duchstein, L. (1986). Techniques for Multi- objective Decision Making in Systems Management, Elsevier Science Publisher B.V.

Tompkins, J. A.,White, J. A., Bozer, Y. A., \& Tan Choco, J. M. A. (2002). Facilities Planning. In John Wiley \& Sons Inc., (3rd Edition), New York.

Ulungu, E. L., \& Teghem J. (1994). Multi-objective Combinatorial Optimization problems: A Survey. Journal of Multi- Criteria Decisions Analysis, 3, 83-104.

Wang, W., Fung. R. Y. K., \& Chai, Y. (2003). Approach of just in time distribution requirements planning for Supply chain management. International Journal of Production Economics, 91, 101-107.

Yokoyama, M. (2002). Integrated optimization of inventory- distribution systems by random local search and a genetic algorithm. Computers and Industrial Engineering, 42, 175-188.

Zhang, D., Zhang, C., Xu, F., \& Zuo, D. (2015). A hybrid genetic algorithm used in vehicle dispatching for JIT distribution in NC workshop, 48, 898-903. 
Zhou, G., Min, H., \& Gen, M. (2002). The balanced allocation of customers to multiple distribution centers in the supply chain network: A genetic algorithm approach. Computers and Industrial Engineering, 43, 251-261.

Zionts, S. (1979). A survey of multiple criteria integer programming methods. Annals of Discrete Mathematics, 5 , 389-398.

\section{Copyrights}

Copyright for this article is retained by the author(s), with first publication rights granted to the journal.

This is an open-access article distributed under the terms and conditions of the Creative Commons Attribution license (http://creativecommons.org/licenses/by/3.0/). 